\title{
A readiness framework to evaluate local economy for an entrepreneurial university
}

\author{
Morteza Borhani, Heidar Amiran, Jamshid Edalatian Shahriari and \\ Mohammad Reza Kabaran Zadeh Ghadim \\ Department of Industrial Management, Central Tehran Branch, \\ Islamic Azad University, Tehran, Iran
}

\begin{abstract}
Purpose - The purpose of this paper is to propose a framework for the transformation from a secondgeneration university to an entrepreneurial university. The work is practical and innovative, which provides the foundation for further work in this field.

Design/methodology/approach - Based on a systematic review of relevant studies on entrepreneurial universities, this paper proposed an evaluation framework with clear logic and practicability. This paper also provided a basis for further research. The restrictions of each factor were defined by the readiness framework, and the consequences of entrepreneurial activities on local economic development were analyzed by using the proposed model. The proposed conceptual framework aided policymakers in completing a much-needed assessment of the impact of organizational policies, practices and structures on the entrepreneurial activities and transformation from second-generation universities to third-generation organizations.

Findings - The proposed readiness framework led to the development of organizational interventions that facilitated successful entrepreneurial activities. The quantitative indicators of different university types were demonstrated in this study. The quantitative validation of the integrated framework suggested that university heads and policymakers can encourage and develop academic entrepreneurship by using a comprehensive systems approach for the identification, protection and commercialization of university's intellectual property. Originality/value - This paper provides a framework for policymakers or decision makers to better understand whether a local university is ready for entrepreneurship. This framework also provides a direction for future quantitative research.
\end{abstract}

Keywords Entrepreneurial universities, Readiness, Local economic development, Framework, Quantitative indicators, Influential factors

Paper type Research paper

\section{Introduction}

This manuscript proposes a readiness framework for a transformation from a secondgeneration university to an entrepreneurial organization based on influential factors and the consequences of entrepreneurial activities on local economic development. A total of six factors and indicators are identified and modeled based on the tutorial entrepreneurship literature. Today, the economies of corporations, countries and successful entrepreneurial universities are deeply influenced by technological developments, short product/service life cycles and global competitiveness (Schwab, 2019). In the meantime, the role of universities in the development of products/services and the commercialization of science has become crucial (Aslani et al., 2015). Various entrepreneurship initiatives are being undertaken at entrepreneurial universities to further transfer science and technologies to industries and

(C) Morteza Borhani, Heidar Amiran, Jamshid Edalatian Shahriari and Mohammad Reza Kabaran Zadeh Ghadim. Published in Journal of Industry-University Collaboration. Published by Emerald Publishing Limited. This article is published under the Creative Commons Attribution (CC BY 4.0) licence. Anyone may reproduce, distribute, translate and create derivative works of this article (for both commercial and non-commercial purposes), subject to full attribution to the original publication and authors. The full terms of this licence may be seen at http://creativecommons.org/licences/by/4.0/legalcode

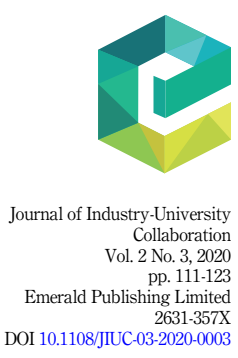

Received 25 March 2020

Revised 19 August 2020 22 August 2020

Accepted 22 August 2020

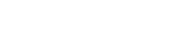


improve the relationship between science, technology and operational activities (Raad and Shirazi, 2020) (Budyldina, 2018). Universities that play a critical role in the economic development of their region are called entrepreneurial universities (Leydesdorff and Etzkowitz, 1998). The development of third-mission activities, i.e. technology transfer and university-industry links, the contributions to regions, new job creation and revenue generation, shaping of entrepreneurial mindsets and innovative culture in society are some of the outstanding features of definitions of the entrepreneurial university.

The intrinsic and economic capacities of the newly industrialized countries are advancing, and national universities and public research organizations are expected to become increasingly important in supporting natural companies to drive them more dynamic and industrialized (Bank, 2018). The characteristics of working with universities may vary greatly depending on whether the industry partner is engaged in new or growing activities (Ankrah and Al-Tabbaa, 2015). In developed economies as well as in newly industrialized countries, the value of research, public education and research-educational projects are of great value in playing an effective role in entrepreneurship and increasing the profits of the national economy as well as in the growth of high-technology activities.

In the medium or long term, the competition in the global economy depends on technologybased strengths (Engineering, 1993). This includes the ability to apply new technology to reach new successful markets as well as develop the skill level of the workforce to develop new products. A university can pay a substantial contribution to the development and institutionalization of the abovementioned elements. Therefore, university-industry collaboration is increasingly expanding, causing market dynamics. The challenges in the global economy have made policymakers and companies expect the universities and research institutes to generate new ideas to accelerate economic innovation and development and, in fact, expect to create a new kind of university (Lacetera, 2009). Therefore, universities are turning from the science and technology center to an ecosystem of innovation and entrepreneurship.

Entrepreneurial university fulfills national and regional development goals and plays a major role in this process. The entrepreneurial university does not only think of producing human capital and ready-to-enter labor force but also pursuing its strategic goals. It produces sustainable technology for economic growth (Guerrero and Urbano, 2010). Entrepreneurial universities think and manage in a global context but operate locally as part of the regional knowledge-based economy structure and it does not operate separately from industry (Pugh et al., 2018).

The fundamental role of universities in the training of a specialist workforce has to fundamentally be changed in various countries, especially in developed countries. The firstgeneration universities were education based. The purpose of these universities was to train specialized human resources. Thereafter, the first academic revolution took place in Germany at the end of the century, during which research-based universities were introduced as second-generation universities. These universities were involved in the research and production of science. Then, the second academic revolution occurred in the second half of the 20th century after the Second World War, during which entrepreneurial universities emerged as the third generation to train the entrepreneurial workforce and connect with industry. In the USA, there were more than 140 entrepreneurial universities created in the 1960s and 1970 s and reached 500 in the 1990s. Entrepreneurial universities in India, the Philippines and Malaysia were also established in Asia. Massachusetts Institute of Technology (MIT), as one of the most prominent third-generation universities in the world, has established a center for training and promoting entrepreneurship among students and faculty with the aim of training managers to succeed in knowledge-based companies. Executives at the university believe that it is not just about inventing a new product, idea or technology but it is also about successful commercialization of innovation (Datta et al., 2014). 
The introduction of entrepreneurial university's activities, as well as the reason why some universities are successful, has become an important research topic in entrepreneurship research. Extensive research studies have been conducted to identify the factors, impacts and consequences of university's entrepreneurial activities. This article investigates the activities, effectiveness and consequences of university's entrepreneurial actions into six main factors:

(1) Factors that focus on individuals and their personalities as key actors in the university's entrepreneurial currents.

(2) Factors that focus on the organizational structure and configuration of the university as a key driver of entrepreneurial flows using university's resources.

(3) Factors that describe the culture and rewards available at the university as factors in the cultural and social development of the university's entrepreneurial activities.

(4) Factors that consider external environmental impacts of university's entrepreneurial practices.

(5) Factors that measure the performance of university's entrepreneurial activities.

(6) Factors that measure the economic impact of university's entrepreneurial activities.

The six research areas mentioned are not completely separate from each other and overlap in areas (Alrajhi and Aydin, 2019). This paper uses these research areas to provide a framework for evaluating the effectiveness and consequences of university's entrepreneurial actions and to explain the factors, components and consequences of transforming a university into an entrepreneurial university. Applying the proposed framework can help policymakers to know the readiness of the university and its region to become an entrepreneurial university.

This article is structured as follows: first, the role and impact of universities' entrepreneurial transformation on the economic development of the region are examined. In Section 3, six separate research factors are introduced and their impact on entrepreneurial universities is described in detail. Section 4 proposes a new framework for evaluating the degree of university's readiness to become an entrepreneurial university, identifying the limitations and shortcomings of existing research. In Section 5, based on the literature review, the proposed theoretical framework based on the introduced factors, components and their impacts and consequences is evaluated. The results and conclusions are presented in Section 6.

\section{Literature review}

This paper fully reviews the literature of entrepreneurial universities and sorts out and analyzes the existing relevant work, showing a full understanding of the work in this field. The traditional mission of the second-generation universities is to research and disseminate knowledge in academic societies and student communities. These universities provide research and development (R\&D) teams and their activities lead to support patents for innovative inventions and to publish high-quality and state-of-the-art manuscripts. They also teach students to become skilled professionals and highly qualified personnel to play essential roles in entrepreneurial activities (Rasmussen, 2006). Universities not only provide resources, laboratories and facilities for the development of technical abilities and outcomes of faculty members but also create an environment for students' growth to acquire explicit and implicit knowledge and tactics through learning and living in the academic environment. Some of the innovation processes of universities (Mohrman et al., 2008) are summarized as follows:

(1) High-quality scientific publications that expand technology and service opportunities. 
JIUC 2,3

114

(2) Training of specialists, professionals, engineers and natural sciences.

(3) Doctoral education is based on knowledge, skills, work teams and human networks.

(4) Collaborating in informal networks, joint R\&D projects, contract research and research activities or exchange of explicit and implicit knowledge-related agreements.

Rather than providing services and products as the primary outcome of academic and scientific research to industry, first- and second-generation universities place great emphasis on education, tacit knowledge and indirect benefits (Abbas et al., 2019). Recent research studies demonstrate that entrepreneurial universities can play a greater role in regional and national economic development. Recent research shows that the attainable role of universities in regional and national economic development can be far greater than the indirect effects of traditional universities. The reasons for the importance of transforming entrepreneurial universities in regional and national economic development can be summarized as follows:

(1) The role of knowledge in the development of national economies and employment.

(2) Technical advances of information and communication technologies (ICTs).

(3) The growing importance of regional high-technology clusters and entities.

The following explain the details of the importance of the transformation into entrepreneurial university in economic development.

\subsection{Increasing share of knowledge and awareness in economic development}

Today, the creation and exploitation of knowledge, especially technology-based entrepreneurial activities for the discovery of new sciences and the pursuit of new opportunities are increasingly accepted and pursued by policymakers (Cantner et al., 2020). The growing dependence of economic development on a nation's abilities to acquire and apply technical, social and economic knowledge in the process of globalization has been accelerated. Technological progress is the prerequisite for continued high economic growth. Today, most comparative advantages are based on technical innovation and the competitive use of knowledge, and, as in the past, abundant natural resources or cheap labor do not account for much of the competitive advantage in economic development. Indeed, economic growth is the result of the process of knowledge accumulation and technological use.

The entrepreneurial university should be considered as a key component of economic strategies that pursue economic development by providing comparative advantages based on the strengthening and exploitation of national knowledge (Guerrero and Urbano, 2010) (Guerrero et al., 2015). This attention will provide the conditions for the development of a knowledge-based society. The rapid acceleration in the rhythm of knowledge creation and dissemination (shortening the lifespan of technologies and products) is the main reason for developing economies to focus on entrepreneurial universities. As a result of the focus and need for economic development on entrepreneurial universities, governments have recently increased the support of universities' technological and entrepreneurial developments to create knowledge-based companies and high-technology entities and the use of academic outputs, products and services.

\subsection{The effect of engineering research and science on economic growth}

Today, the world is experiencing a shift in the way people work, how organizations are structured and how businesses compete in the aftermath of advances in ICT. ICT has 
transformed most of the competing markets from local to global, and competing businesses may offer products and services from anywhere in the world. The need for economies to compete in such a competitive environment is to accelerate the growth of knowledge by a new generation of universities. The continuous learning process is itself one of the primary requirements to accelerate knowledge development. Therefore, it is imperative that entrepreneurial universities, which have traditionally been the centers of gathering, creating and disseminating new knowledge, should provide the conditions to enhance the competitive advantage of their areas.

\subsection{The role of technological clusters and knowledge-based companies in economic development}

Nowadays, universities should contribute to the development of national economies, in addition to producing and disseminating knowledge within the academic community and the indirect effects on economic development. The third-generation universities support deployment of regional technological entities and high-technology companies by stimulating and disseminating business knowledge through the activation. One of the important aspects of entrepreneurial universities and high-technology companies in economic development is the possibility of attracting foreign direct investment into the country. From the perspective of multinational companies, the location of high value-added R\&D projects is influenced by human capital and regional R\&D capability (Capello and Nijkamp, 2019). Economies with high-technology infrastructure and start-ups are better able to attract student investment from multinationals.

\section{The research work design and the research method}

The framework proposed in this paper is based on existing theories. The common elements [18] among successful entrepreneurial institutions are summarized as follows:

(1) Most successful entrepreneurial universities have strong top-down leadership and policies that support, accelerate and encourage the process of entrepreneurial activity and integrate entrepreneurial goals with traditional university academic values, thereby synergizing trends.

(2) Most successful entrepreneurial universities owe their success to extensive communication and collaboration with industry in cross-cutting research projects. To this end, entrepreneurial universities have policies and procedures for entrepreneurial activities and are supported and encouraged by structures such as industrial communications offices and flexible contracting practices.

(3) The sources of funding for successful entrepreneurial universities vary, and although most of the funding for these universities is still funded by the government, funding from industry as well as private charities is also available.

(4) One of the requirements for successful entrepreneurial universities is to have a strong academic base and a comprehensive effort to improve their academic performance.

(5) To succeed in entrepreneurial universities, it is necessary to develop an entrepreneurial culture at the university and change the culture of individuals to accept it while maintaining the core values of the institution.

The influential factors and consequences of university's entrepreneurial activities can be listed in six primary research groups or domains which are as follows: 
JIUC
2,3

116

\subsection{Scientific relationship, industrial and personality characteristics of university entrepreneurs}

The entrepreneurial attributes, personality traits, motivations, disposition and experiences of individuals play a prominent role in influencing and shaping entrepreneurial activities. The psychological framework is also very effective to explain the output of service or product departure from universities (Shwetzer Herrera et al., 2019). The individual's abilities, personalities and will have a great impact on the entrepreneurial behavior of academics to succeed. The entrepreneurial behavior deters the quantity and quality of products. Academic entrepreneurs with outgoing, extroverted personalities were more likely to engage in entrepreneurial activities. Personal characteristics such as the need for achievement, the desire for independence and an internal locus of control were common in both groups. University entrepreneurs tended to be older and more scientifically experienced than "typical" high-technology entrepreneurs. Scientific stars collaborating with firms had substantially higher citation rates than pure academic stars.

\subsection{Resources and resources at the university include funding, brands, laboratories, growth and research centers and faculty}

Although the general organizational theories of universities have concerned on the impact of environmental forces on academic entrepreneurial activities, rather than focusing on the broad economic or social forces, the organizational and human aspects of the university can be addressed and the relationship between entrepreneurial activities and the level and nature of research funding, the quality of the researchers and the nature of the research within the university and the presence of technology incubators should be excavated.

\subsection{Entrepreneurial culture, policies, rules, structures and promotion opportunities that enhance entrepreneurial activities and facilitate knowledge-based business}

A university's entrepreneurial activities are a reflection of institutional behavior. Universities that have cultures that support commercialization have a higher level of business and higher levels of entrepreneurial activity. In contrast, academic environments that do not encourage entrepreneurship have less entrepreneurial activity. The university's social norms and expectations are the main determinants of commercialization (O'Shea et al., 2004). Faculty members at some universities have greater motivation for entrepreneurial activity than their counterparts at other universities because of the inspiration provided by former university entrepreneurs at their university (Fayolle and Redford, 2014). Faculty decisions on entrepreneurial activities are subject to social conditions. Entrepreneurial pioneers struggle to make new academics believe that entrepreneurial activities are acceptable and desirable (Riazi, 2018, pp. 16-32). In contrast, academic environments do not encourage entrepreneurship to inhibit entrepreneurial activity. Academic unwillingness to engage in entrepreneurial behavior may be exacerbated by the attitudes and behaviors of senior individuals such as professors or heads of departments (Emami and Khajeheian, 2019). Local group norms are important in predicting active participation in commercialization (Bercovitz and Feldman, 2008).

(1) Environmental factors affecting university and academic entrepreneurial activities.

There are three broader economic factors that have the greatest impact on entrepreneurship activities in universities (Kirkley, 2016) and are as follows: (1) access to investment for the formation of advanced companies, (2) legalization of inventions and (3) knowledge infrastructure in the region. National policies that allow for the invention of patents for academic inventors inhibit entrepreneurial activity and lead to anti-entrepreneurial attitudes among faculty and university administrators that do not benefit from the entrepreneurial 
activity of inventors (Goldstein, 2010). Knowledge infrastructure of a region is another key environmental factor in determining entrepreneurial activities. Ease of access to critical expertise, networks and more knowledge in high-technology clusters enhances entrepreneurial activities.

(2) Performance of side jobs, multitasking and service records.

Few but growing studies have been conducted to evaluate the performance of university's entrepreneurial activities. One of the performance indicators is the high survival rate of university affiliates relative to the average survival of new firms. Lower rates of failure in entrepreneurial activities at entrepreneurial universities are another indicator of performance appraisal. Studies show that new technology firms are likely to survive and continue to operate if radical technologies are exploited and if they have a broad patent. Measuring the amount of direct and indirect communication with investors is one of the indicators of performance appraisal and one of the most critical determinants of the success of technological activities that directly reduce the likelihood of product or service failure at entrepreneurial universities. A combination of academic and surrogate entrepreneurs might be the best approach for developing successful technology-based entrepreneurial activities. So, the composition of core entrepreneurs can be considered as a performance indicator for an entrepreneurial university.

Entrepreneurial activities have four stages including the research, opportunity setting, pre-reorganization and reintegration phases, as well as four critical milestones for progress to the next development stage including opportunity recognition, entrepreneurial commitment, credit and sustainability thresholds. At the entrepreneurial university, indicators for evaluating their performance and success at these stages and these critical points should be defined and monitored continuously. The success of entrepreneurial activities depends on the ability of entrepreneurs to communicate with a wide range of different stakeholders such as financial institutions, research laboratories and the customer. The breadth of university entrepreneurs' relationships and their experience in capturing market capital is another indicator of the performance evaluation of entrepreneurial universities.

(3) Measuring the impact of university's entrepreneurial activities on economic development of the region.

Start-ups and entrepreneurial activities directed by entrepreneurial universities are highly effective in enhancing the economic power and market penetration of high-technology companies. They also create new job opportunities, especially for a highly educated workforce as well as increasing economic added value and ultimately economic development (Stijn et al., 2018).

\section{Analyzing and results}

In this section, the framework of the third generation of university transformation preparation is presented and discussed. Entrepreneurial universities around the world have received much attention from scholars and policymakers, and the move toward the transformation of universities into entrepreneurial universities has been welcomed. This study examines the causes and factors behind the success of some of these third-generation universities and assesses the conditions for converting a second-generation university to an entrepreneurial university. Different perspectives are offered on why some universities are at higher levels of successful entrepreneurial activities. This section provides a framework for evaluating university's readiness to become a third-generation university based on the proposed research policy and the research methods. 
JIUC 2,3

118

According to the theory of systems and advanced modeling tools, there is a critical demand to identify systematic changes and to answer why some universities have become more relatively successful in the third generation and when a university is ready to change its traditional policies into an entrepreneurial university. Most of the research studies, which were done to evaluate the readiness of universities to become third-generation universities and to change policies to encourage and support entrepreneurial activities, are theoretical and models that have been offered solely in expressing some relationships between events without accountability explanations (Darling-Hammond et al., 2019). Thus, further studies that can explain, from an organizational perspective, why some universities succeed in supporting and encouraging entrepreneurial activities and technology-based services/ products are still of interest to scientists and policymakers. The complex processes within institutions are required to address the different forms of entrepreneurial activities and the complex causes and patterns that lead some, but not all, academics to engage in technologybased ventures in entrepreneurial universities.

The social setting of the institution and social environment established by other faculty members in the university play a very important role in entrepreneurial activities and the process of becoming an entrepreneurial university. The difference in the number of entrepreneurial activities at different universities is a direct reflection of the degree to which the culture of cooperation made them important determinants of the academic status (Perkmann et al., 2013). The role of the individual personality in entrepreneurial activities should be identified and taken into account in the framework or framework for measuring readiness to change into a third-generation university (Coduras et al., 2016).

The needs of institutional authorities seeking to enhance entrepreneurship on campus should be taken into account in the design of the framework. The different forms of entrepreneurial activity in higher education and the roles that institutions play in start-ups should also be taken into account. Nowadays, some research studies are being conducted on the implications of entrepreneurial activities and the transformation of universities to become entrepreneurial universities in the development of the regional economy. Most of the results of these studies call for further reflection on the potential weaknesses of the innovation system of universities that have entered the third-generation university phase before they are prepared. Problems with the tensions created by faculty's performance between departments and colleges within such universities have raised concerns about unsuccessful entrepreneurial activities.

Since the process of converting a traditional university into an entrepreneurial university is longitudinal, there is a need to research longitudinal structures in addition to traditional cross-sectional studies. From a methodological point of view, different methods of data collection are needed to influence the evaluation of university's entrepreneurship programs as well as to assess university's readiness to become a third-generation university. While preparing the data, in addition to carefully recording, documenting and explaining changes and interinstitutional variations which were made in the process of establishing an entrepreneurial university including policies, processes and incentives, the structural complexities, as well as the richness of universities dynamics, should be captured and analyzed.

For the reasons mentioned above, it is necessary to use quantitative and qualitative hybrid simulations to evaluate the proposed systems for modeling the process of transforming a university into a third-generation university as well as evaluating its readiness for such change. Quantitative-based evaluation and qualitative evaluation results have been used to confirm the proposed framework of this paper. There are some limitations to data collection and modeling of academics' viewpoints and their perception of the quality of entrepreneurial experiences that complicate the proposed framework. Thus, in addition to employing quantitative methods, extensive and rigorous research requires the use of 
different types of qualitative methods ranging from focus group interviews to individual interviews to explain how academics understand their experiences within their institutional framework. Fortunately, to reduce the complexity of the proposed framework, some simpler methods can be exploited to provide some of the academic entrepreneurial tendencies. Such practices allow policymakers and academics to make meaningful decisions about how prepared they are to become a third-generation university. The quantitative indicators of different university types are demonstrated in Table 1.

The scientific and research productivity of universities can be exploited to determine the generation of the university. The publication and citation indices (commercial research income per academic staff, and share of R\&D incomes in total) as well as their funding sources (state, business and foreign) are some of the indicators to measure the university's productivity which were typically provided in Figure 1. One of the distinctive indicators of potential entrepreneurial universities is that most publication activities are related to a share of non-budgetary R\&D incomes, including business and international funding sources. In these universities, the quality and quantity of publication activity (via co-publications, disclosure of research results, etc.) are enhanced in close cooperation of academic staff with businesspeople. Entrepreneurial universities have typically approached internationalization strategies (the volume of foreign-financed $R \& D$ and international publication and citation indices) and actively engaged in joint international research projects and academic exchange with foreign universities. Promotion of entrepreneurial initiatives and engaging in technology transfer and regional innovation initiatives led to more publication activities.

\section{Discussions and its practicality and research implications}

This section integrates the abovementioned sociopsychological perspectives into a readiness framework toward the third-generation university. The proposed readiness framework exploited several influence factors for the transformation of a second-generation university into a third-generation organization in the domain of entrepreneurial activities and it also quantitatively indicates consequences on local economic development due to entrepreneurial universities. This framework provides a useful organizing scheme for understanding to identify the determinants of entrepreneurial activities within universities and for explaining the determinants and consequences of entrepreneurial activities.

\begin{tabular}{|c|c|c|c|c|}
\hline Indicator & $\begin{array}{l}\text { First-generation } \\
\text { university }\end{array}$ & $\begin{array}{l}\text { Second-generation } \\
\text { university }\end{array}$ & $\begin{array}{l}\text { Third-generation } \\
\text { university }\end{array}$ & \\
\hline $\begin{array}{l}\text { Publications indexed in scientific citation } \\
\text { database per } 100 \text { academic staff }\end{array}$ & 139.8 & 139.3 & 186 & \\
\hline $\begin{array}{l}\text { Web of Science and Scopus publications } \\
\text { per } 100 \text { academic staff }\end{array}$ & 90.2 & 24 & 36.8 & \\
\hline $\begin{array}{l}\text { Non-budgetary incomes in total income } \\
(\%)\end{array}$ & 38.6 & 43.3 & 61.5 & \\
\hline $\begin{array}{l}\text { Non-budgetary R\&D incomes in total } \\
\text { income }(\%)\end{array}$ & 23.8 & 20.4 & 10 & \\
\hline $\begin{array}{l}\text { Non-budgetary incomes in total } \mathrm{R} \& \mathrm{D} \\
\text { income }(\%)\end{array}$ & 56.9 & 75.4 & 73.8 & \\
\hline International R\&D incomes & 17,706 & 8,174 & 4,061 & $\begin{array}{l}\text { Table } 1 . \\
\text { Indicators and their }\end{array}$ \\
\hline$R \& D$ incomes per 1 academic staff & 402.3 & 575.1 & 441.9 & personalities as key \\
\hline Start-ups and spin-offs & 24.4 & 5.6 & 1.7 & personidors in the \\
\hline Total academic staff & 940.6 & 1,229 & 367 & university's \\
\hline $\begin{array}{l}\text { Young academic staff (non-PhD under } 30 \\
\text { years, Ph.D. under } 35 \text { years) }(\%)\end{array}$ & 21.5 & 12.1 & 18.4 & $\begin{array}{r}\text { entrepreneurial } \\
\text { currents }\end{array}$ \\
\hline
\end{tabular}




\section{JIUC 2,3}

120

\section{Figure 1.}

Some of the quantitative indicators of different university types

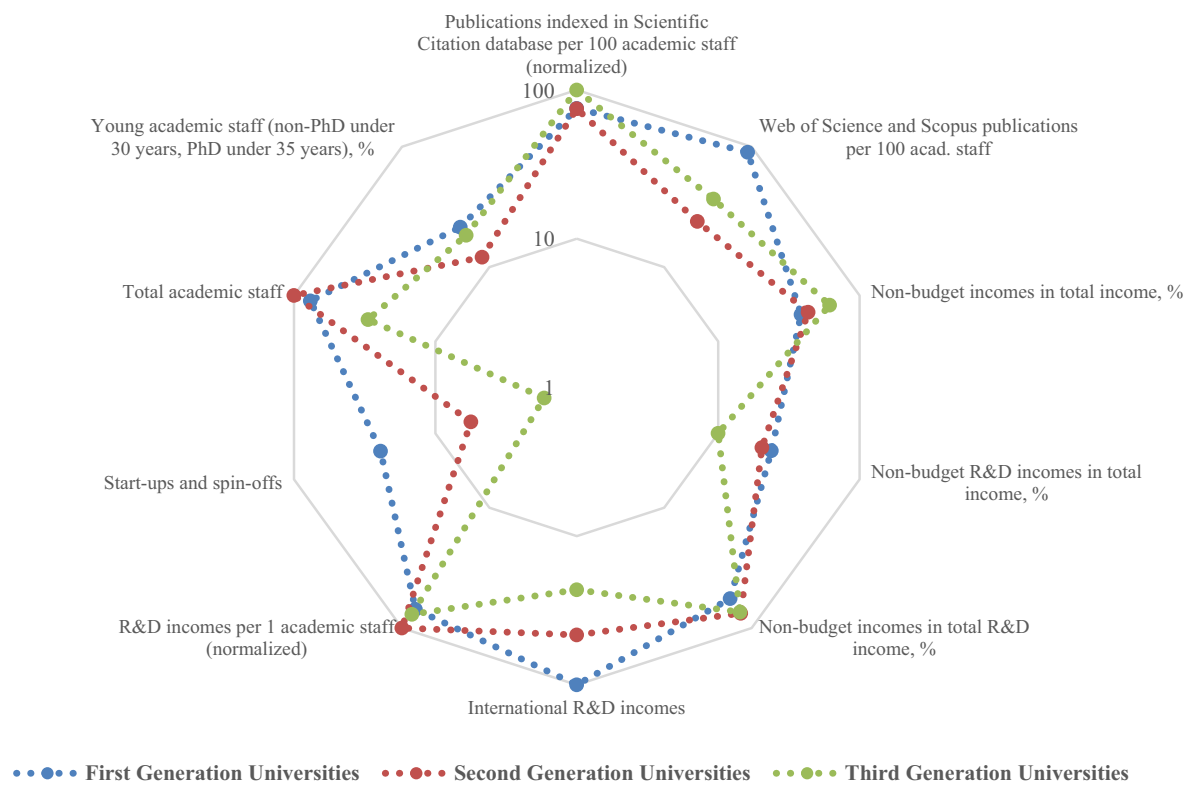

The proposed readiness framework is presented in Figure 2 based on a conceptual integration of influencing factors for transforming a second-generation university to a thirdgeneration organization and quantitatively indicates consequences of the third-generation university on local economic development. Base on the proposed model, the readiness for a third-generation university in the local economy does not only depend on the characteristics of individual academics but also depends on variation in environments and university contexts. Also, four factors influence the rate of entrepreneurial activities in secondgeneration universities to transform into a third-generation organization:

(1) Individual characteristics including academic entrepreneurs, motivations such as career experiences and faculty networking are part of the academic's reasons for engaging in entrepreneurial activity and accelerate the transformation toward a third-generation university.

(2) Organizational resources including faculty quality, interdisciplinary research centers, nature of research, technology transfer, resources and expertise, the process of technology transfer, the commercial orientation of research, R\&D funding, type of technologies created, patent production, entrepreneurship development programs and presence of incubators are some of the attributes of universities which have to be measured before creating a third-generation university by organizationfocused studies.

(3) Institutional and cultural characteristics including leadership mission goals, history and tradition and also faculty and department culture in university and proposed rewards for entrepreneurial activities are some of the broader social contexts of the university which influence the success of transformation from a university to an entrepreneurial university.

(4) Environmental factors including seed and venture capital availability, regional infrastructure and environment, university's intellectual property policy and local 


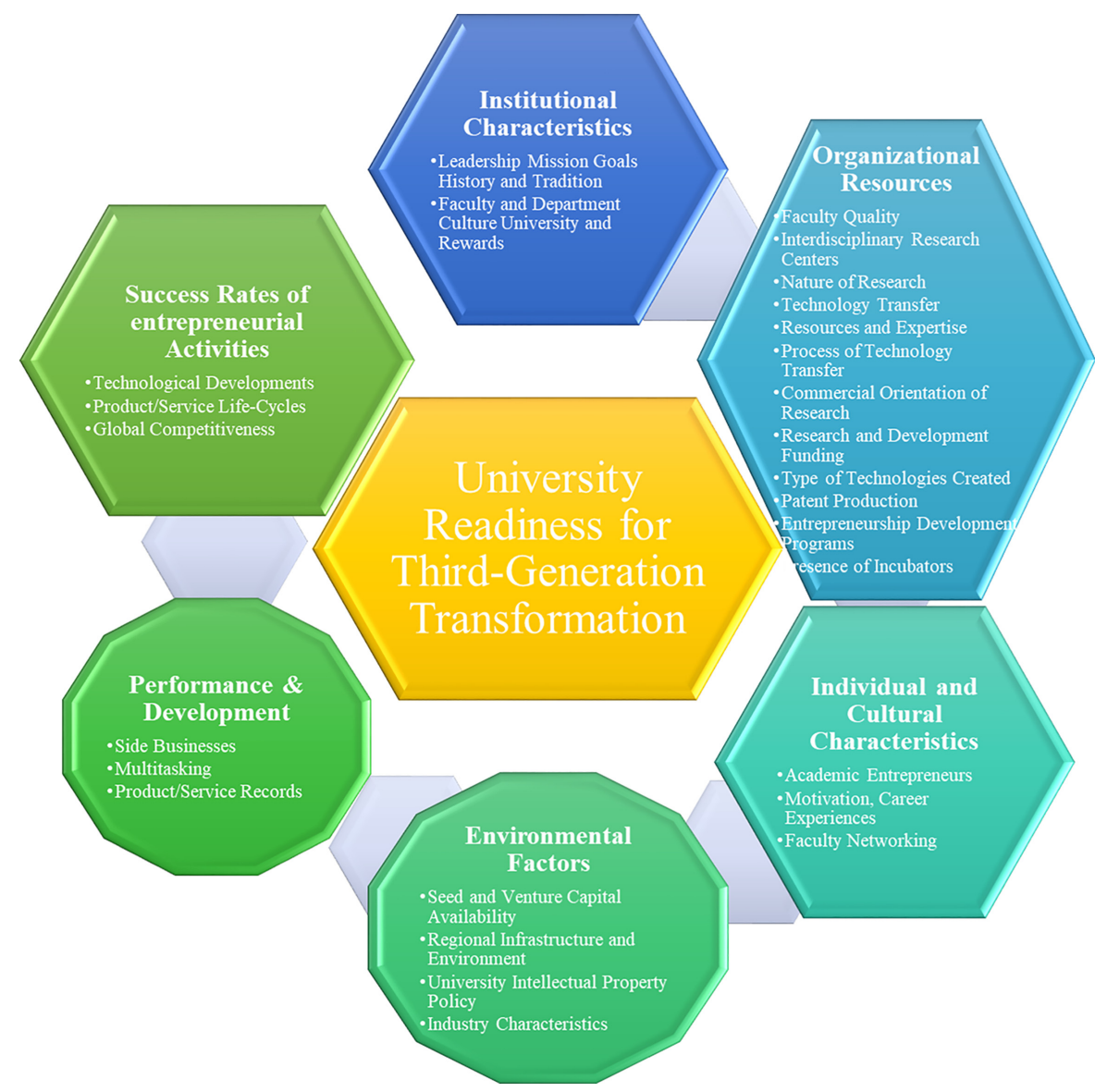

Entrepreneurial university

industry characteristics are some of the external characteristics that impact readiness for the creation of a third-generation university.

The consequences of entrepreneurial activities on local economic development can be quantitatively modeled by two further indicators:

(1) The development and performance of side jobs, multitasking and product/service records in the local economy.

(2) The success rates of the technological developments, product/service life cycles and global competitiveness on the regional economy.

\section{Conclusions}

The conclusions of this paper are based on an assessment of existing studies and the analysis of data. The Conclusions section shows the viewpoint of this paper appropriately. This paper is a systematic approach to measure the readiness of second-generation universities to transform into entrepreneurial universities. The proposed framework is based on six completely different studies including influence factors and quantitative indicators of the 
JIUC 2,3

consequences of entrepreneurial activities on local economic development. This paper argues for the existence of an underlying set of individual and contextual factors of entrepreneurial activities that need to be accepted by the local economy before initiating transformation to have a third-generation university. Also, the two other primary indicators are identified (i.e. development and performance of entrepreneurial activities and the economic impact of entrepreneurial activities) to provide a parsimonious description of the outcomes of entrepreneurial activities. The limitations of the entrepreneurial activities of the different kinds of universities are quantitatively provided by this paper. The proposed readiness framework can draw generalizations of the entrepreneurial activities and their consequences on local economic development and can help policymakers to understand how entrepreneurial universities can contribute to both their traditional functions and the added function of making the regional or national economy more competitive.

\section{References}

Abbas, A., Avdic, A., Xiaobao, P., Hasan, M.M. and Ming, W. (2019), "University-government collaboration for the generation and commercialization of new knowledge for use in industry", Journal of Innovation and Knowledge, Vol. 4 No. 1, pp. 23-31.

Alrajhi, A. and Aydin, N. (2019), "Determinants of effective university-business collaboration: empirical study of Saudi universities", Journal of Industry-University Collaboration, Vol. 1, pp. 169-180.

Ankrah, S. and Al-Tabbaa, O. (2015), "Universities - industry collaboration: a systematic review", Scandinavian Journal of Management, Vol. 31 No. 3, pp. 387-408.

Aslani, A., Eftekhari, H., Hamidi, M. and Nabavi, B. (2015), "Commercialization methods of a new product/service in ICT industry: case of a science and technology park", Organizacija, Vol. 48 No. 2, pp. 131-139.

Bank, W. (2018), World Development Report 2019: The Changing Nature of Work, World Bank Publications, Washington, DC.

Bercovitz, J. and Feldman, M. (2008), "Academic entrepreneurs: organizational change at the individual level”, Organization Science, Vol. 19 No. 1, pp. 69-89.

Budyldina, N. (2018), "Entrepreneurial universities and regional contribution", International Entrepreneurship and Management Journal, Vol. 14, pp. 265-277.

Cantner, U., Cunningham, J.A., Lehmann, E.E. and Menter, M. (2020), "Entrepreneurial ecosystems: a dynamic lifecycle model", Small Business Economics.

Capello, R. and Nijkamp, P. (2019), Handbook of Regional Growth and Development Theories, Edward Elgar Publishing, Cheltenham, ISBN 9781788970013, doi: 10.4337/9781788970020.

Coduras, A., Saiz-Alvarez, J.M. and Ruiz, J. (2016), "Measuring readiness for entrepreneurship: an information tool proposal", Journal of Innovation and Knowledge, Vol. 1 No. 2, pp. 99-108.

Darling-Hammond, L., Flook, L., Cook-Harvey, C., Barron, B. and Osher, D. (2019), "Implications for educational practice of the science of learning and development", Applied Developmental Science, Vol. 24 No. 2, doi: 10.1080/10888691.2018.1537791.

Datta, A., Mukherjee, D. and Jessup, L. (2014), "Understanding commercialization of technological innovation: taking stock and moving forward”, R\&D Management, Vol. 45 No. 3, pp. 215-249.

Emami, A. and Khajeheian, D. (2019), "Social norms and entrepreneurial action: the mediating role of opportunity confidence", Sustainability, Vol. 11 No. 1, p. 158.

Engineering, N.A. (1993), Mastering a New Role: Shaping Technology Policy for National Economic Performance, The National Academies Press, Washington, DC. doi: 10.17226/2103.

Fayolle, A. and Redford, D.T. (2014), Handbook on the Entrepreneurial University, Edward Elgar Publishing, Northampton, MA. 
Goldstein, H.A. (2010), "To what extent is academic entrepreneurship taken for granted within research universities?", Higher Education Policy, Vol. 23 No. 1, pp. 1-15.

Guerrero, M. and Urbano, D. (2010), "The development of an entrepreneurial university", Journal of Technology Transfer, Vol. 37, pp. 43-74.

Guerrero, M., Cunningham, J. and Urbano, D. (2015), “Economic impact of entrepreneurial universities' activities: an exploratory study of the United Kingdom", Research Policy, Vol. 44 No. 3, p. 748.

Kirkley, W.W. (2016), "Creating ventures: decision factors in new venture creation”, Asia Pacific Journal of Innovation and Entrepreneurship, Vol. 10 No. 1, pp. 151-167.

Lacetera, N. (2009), “Academic entrepreneurship”, Managerial and Decision Economics, Vol. 30 No. 7 , pp. 443-464.

Leydesdorff, L. and Etzkowitz, H. (1998), “Triple helix of innovation: introduction”, Science and Public Policy, Vol. 25 No. 6, pp. 358-364.

Mohrman, K., Ma, W. and Baker, D. (2008), "The research university in transition: the emerging global model", Higher Education Policy, Vol. 5, pp. 5-27.

O'Shea, R., Allen, T.J., O'Gorman, C. and Roche, F. (2004), "Universities and technology transfer: a review of academic entrepreneurship literature", Irish Journal of Management, Vol. 25 No. 4, pp. 11-29.

Perkmann, M., Tartari, V., McKelvey, M., Autio, E., Broström, A., D’Este, P. and Sobrero, M. (2013), "Academic engagement and commercialisation: a review of the literature on universityindustry relations", Research Policy, Vol. 42 No. 2, pp. 423-442.

Pugh, R., Lamine, W., Jack, S. and Hamilton, E. (2018), "The entrepreneurial university and the region: what role for entrepreneurship departments?", Journal European Planning Studies, Vol. 26, pp. 1835-1855, (9: EPS 25th Anniversary Special Issue).

Raad, N.G. and Shirazi, M.A. (2020), "A project portfolio selection framework for transforming Iranian universities into entrepreneurial institutions", Journal of Industry - University Collaboration, Vol. 2 No. 1, pp. 2-21.

Rasmussen, E. (2006), "Models for university technology transfer operation: patent agency and 2g", International Journal of Technology Transfer and Commercialisation, Vol. 5 No. 4, pp. 291-307.

Riazi, Z. (2018), "Investigating the relationship between educational dimensions of entrepreneurial organizational culture and creativity in faculty members of Tehran university", Iranian Journal of Educational Sociology, Zohreh Riazi, Vol. 1 No. 8, pp. 16-32.

Schwab, K. (2019), The Global Competitiveness Report, World Economic Forum, Geneva.

Shwetzer Herrera, C., Maritz, A. and Nguyen, Q.A. (2019), "Entrepreneurial ecosystems: a holistic and dynamic approach", Journal of Industry-University Collaboration, Vol. 1 No. 2, pp. 79-95.

Stijn, N.V., Rijnsoever, F.J. and Veelen, M.V. (2018), "Exploring the motives and practices of university-start-up interaction: evidence from Route 128", The Journal of Technology Transfer, Vol. 43, pp. 674-713.

\section{Corresponding author}

Heidar Amiran can be contacted at: hey.amiran@iauctb.ac.ir
Entrepreneurial university 